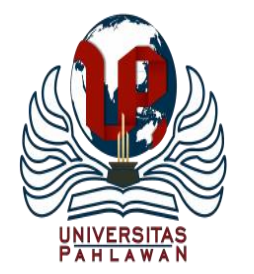

Edukatif : Jurnal Ilmu Pendidikan Volume 2 Nomor 2 Tahun 2020 Halm 187-

EDUKATIF: JURNAL ILMU PENDIDIKAN

Research \& Learning in Education

https://edukatif.org/index.php/edukatif/index

\title{
Kebijakan Supervisi Dan Penilaian Kinerja Guru Guna Mewujudkan Kompetensi, Kinerja, Mutu Pendidikan Di Sekolah Dasar Menuju Abad 21
}

\author{
Fitriadi $^{1}$, Sufyarma Marsidin ${ }^{2}$, Ahmad Sabandi $^{3}$ \\ Pendidikan Dasar, Universitas Negeri Padang ${ }^{1,2,3}$ \\ e-mail : $\underline{\text { fitriadi0107@ gmail.com }}{ }^{1}, \underline{\text { sufyarma1954@ gmail.com }}^{2}, \underline{\text { sabandi@ fip.unp.ac.id }}^{3}$
}

\begin{abstract}
Abstrak
Artikel ini menelaah dan menganalisis kebijakan standar supervisi dan penilaian kinerja guru di sekolah dasar. Dalam hal yang diketahui dalam menciptakan capaian tujuan pendidikan yang diharapkan, maka sistem pembelajaran harus mengarah pada penilaian kinerja guru. Kinerja guru merupakan upaya untuk menjadikan guru yang profesional dan mahir dalam bidangnya seorang guru. Dengan profesionalnya seorang guru dalam menjalankan tugasnya tentu pembelajaran di dalam kelas lebih efektif dan akhirnya keefektifan proses pembelajaran tentu ketuntasan belajar tercapai dan akhirnya berjalan waktu hasil belajar meningkat berperan penting meningkatnya mutu pendidikan. Berdasarkan penelitian melalui kajian pustaka yang dilakukan, maka diperoleh beberapa kebijakan yang harus dilakukan guru dalam menjalankan tugasnya. Untuk itu manfaat dari penelitian ini adalah upaya yang dilakukan guru dalam menerapkan standar proses yang telah ditentukan dari satuan pendidikan agar meningkatnya kinerja guru dalam pembelajaran. Adanya kebiijakan pemerintah tentang sertifikasi yang memberikan tunjanggan-tunjangan lain yang menjajikan, sehingga profesi guru sangat dimintai oleh masyarakat. Pemerintah menuntut guru menjadi guru yang profesional dalam menjalankan tugasnya.
\end{abstract}

Kata kunci : kebijakan, kinerja guru, sekolah dasar

\begin{abstract}
This article reviews and analyzes the standard policy of supervision and assessment of teacher performance in primary schools. In terms of what is known in creating the expected educational goals, the learning system must lead to an assessment of teacher performance. Teacher performance is an effort to make teachers who are professional and proficient in their fields as teachers. With the professionalism of a teacher in carrying out their duties of course learning in the classroom is more effective and finally the effectiveness of the learning process of course mastery learning is achieved and finally running time as learning outcomes increase plays an important role in improving the quality of education. Based on research through literature review, several policies must be obtained by the teacher in carrying out their duties. For this reason, the benefits of this research are the efforts made by the teacher in applying the predetermined process standards from the education unit so that the teacher's performance improvement in learning increases. There are government policies on certifications that provide other benefits that are promising, so that the teaching profession is highly sought after by the community. The government demands that teachers become professional teachers in carrying out their duties.
\end{abstract}

Keywords: policy, teacher performance, elementary school

Copyright (c) 2020 Fitriadi, Sufyarma Marsidin, Ahmad Sabandi

$\triangle$ Corresponding author :

Address : Universitas Negeri Padang

ISSN 2656-8071 (Media Cetak)

Email : fitriadi0107@gmail.com

ISSN 2656-8063 (Media Online)

DOI: https://doi.org/10.31004/edukatif.v2i2.120

Edukatif : Jurnal Ilmu Pendidikan Vol 2 No 2 Tahun 2020 p-ISSN 2656-8063 e-ISSN 2656-8071 
188 Kebijakan Supervisi Dan Penilaian Kinerja Guru Guna Mewujudkan Kompetensi, Kinerja, Mutu Pendidikan Di Sekolah Dasar Menuju Abad 21 - Fitriadi, Sufyarma Marsidin, Ahmad Sabandi DOI: https://doi.org/10.31004/edukatif.v2i2.120

\section{PENDAHULUAN}

Adanya kebijakan pemerintah tentang sertifikasi yang memberikan tunjangan-tunjangan lain yang menjanjikan, sehingga profesi guru sangat diminati oleh masyarakat. Pemerintah menuntut guru menjadi guru yang profesional dalam menjalankan tugasnya. Menurut Mulyasa (2013), seharusnya peningkatan mutu pendidikan ditunjang oleh guru yang profesional juga dan bermutu yang mengemban tugas dan kinerjanya berkualitas dalam rangka melahirkan insan yang memiliki kualitas melalui kegiatan proses belajar mengajar.

Suatu lembaga pendidikan yaitu hal yang sangat diperlukan. Melakukan monitoring dan evaluasi serta memprogramkan pendidikan masa akan datang diperlukan penilaian kineja secara tepat dan terimplementasi. Kinerja seorang guru merupakan pondasi awal dalam meningkatan mutu pendidikan. Dengan demikian, peningkatan kualitas pendidikan harus dapat diukur kinerjanya, cara informasi, data dan laporan. Laporan kinerja guru sangat tepat dalam menentukan mutu pendidikan, sehingga semua informasi, layanan pendidikan dan pembelajaran dilakukan taktik efektif, efesien, dan akuntabel. Penilaian kinerja seorang guru butuh kepribadian dan kemampuan profesional yang standar yang dapat dipertanggung jawabkan.

Dengan demikian penilaian kinerja merupakan akuntabilitas dari seorang guru dan instansi kerja terhadap pegawainya. Kinerja seorang guru dan kepala sekolah tidak hanya bertanggung jawab terhadap orang tua dan masyarakat saja. Namun bertanggung jawab terhadap peningkatan mutu pendidikan di negara kita. Pengawas harus menguasai kompetensi dalam penilaian kineja baik guru, kepala sekolah dan staf atau pegawai sekolah.

UU No 20 Tahun 2003 mengenai sistem pendidikan nasional sudah menerapkan taksonomi dalam bentuk rumusan sikap, pengetahuan dan keterampilan. Proses pembelajaran dapat diarahkan pada perkembangan ketiga ranah tersebut secara keseluruhan yang artinya perkembangan ranah tersebut tidak dapat dipisahkan satu sama lainnya. Dengan demikian proses pembelajaran secara utuh dapat melahirkan kualitas individu yang mencerminkan keutuhan dari penguatan sikap, pengetahuan dan keterampilan tersebut.

\section{METODE PENELITIAN}

Metode yng diterapkan pada kajian ini ialah dengan library research. Library research yaitu serangkaian kegiatan yang berhubungan dengan mengumpulkan data kepustakaan, mencatat, membaca dan mengolah bahan tersebut.

Pnelitian ini disebut penelitian pustaka karena data-data atau bahan yang digunakan dalam menyelesaikan sebuah penelitian berasal dari pustaka berupa buku, kamus, dokumen ensiklopedi, jurnal, majalah dan sebagainya (Harahap, 2014).

Oleh karena itu, pengumpulan data dalam penelitian dilakukan dengan menelaah atau mengeksplorasi beberapa buku, jurnal, dan dokumen cetak maupun elektronik serta sumber data atau informasi lainya yang sesuai dengan penelitian yang dilakukan. 
189 Kebijakan Supervisi Dan Penilaian Kinerja Guru Guna Mewujudkan Kompetensi, Kinerja, Mutu Pendidikan Di Sekolah Dasar Menuju Abad 21 - Fitriadi, Sufyarma Marsidin, Ahmad Sabandi

DOI: https://doi.org/10.31004/edukatif.v2i2.120

\section{HASIL DAN PEMBAHASAN PENELITIAN}

\section{Pengertian Penilaian Kinerja Guru Dan Kepala}

\section{Sekolah}

Menurut Mufah (2011) secara harfiah kata penilaian berasal dari Bahasa Inggris "evaluation", value artinya nilai. Menurt Anas Sudiono mengemukakan penilaian menunjukan pada suatu tindakan atau suatu proses untuk menentukan angka. Sedangkan A.Fajar, penilaian adalah dapat diartikan kiat memperoleh informasi yaitu secara berkala, menyeluruh dan berkesinambungan dalam proses pembelajaran dilakukan oleh seorang guru dan kepala sekolah. Dengan demikian penialian adalah suatu proses atau kegiatan yang sistematis, berkelanjutan dan menyeluruh dalam rangka menjamin dan penetapan kualitas berbagai komponen berdasarkan pertimbangan dan kriteria tertentu merupakan bentuk pertangungjawaban seorang dalam melaksanakaan pekerjaanya.

Kineja berawal dari kata job performance yaitu prestasi kerja yang dicapai seorang dalam melaksanakan tugas utama, fugsi dan tangung jawab yang diberikan kepada seseorang. Kineja diartikan tingkat atau derajat pelaksanan tugas seorang guru atas kopetensi yang dimilikinya. kineja dapat dimaknai sebagai ekpresi potensi seorang berupa perilaku atau cara untuk seseorang dalam melaksanakan tugasnya.

Penilaian Kineja Guru (PKG) dapat diartikan sebagai suatu upaya untuk memperoleh gambaran tentang pengetahuann, keterampilan, nilai dan sikap guru selama menjalankan tupoksinya seorang guru berupa penampilan, perbuatan dan prestasi kerjanya sesuai yang tertera pada Peraturan Menteri Pendayagunan Aparratur
Negaradan Repormasi Birokkrasi Nomor 16 Tahun2009 Yaitu Tentangjabatan Funngsional Guruu Dan Angka kredit.

Penilaian Kineja Kepala Sekolah (PKKS) merupakan proses pengumpulan, pengolaan, analisiss dan interprestasi data tentang kualitas pekerjaan kepala sekolah sesuai tupoksinya sebagai kepala sekolah. Tugas inti kepalah sekolah yaitu merencanakan program, melaksanakan program, melaksanakan pengawasan, dan melaksanakan kepemimpinan untuk sekolah, serta menerapkan sistem informasi sekolah.

\section{Pendekatan Yang Digunakan Dalam Proses Penilaian}

Menurut Mulyasa (2012) pendkatan dalam penilaian kenrja dapat dlakukan dengan beberap cara diantaranya :

1. Penilaian berpokus pegawai

2. Penilaian berdasar dasar perilaku

3. Penilaian berdasar hasill yang capai

4. Penilaian Gllobal

\section{Tujuan Penilaian Kinerja}

Menurut PSDMPMP (2012) PKG pada hakikatnya adalah untuk membina dan menembangkan guru profesional yang dikerjakan dari guru oleh guru dan untuk guru.

Hasil penilaiann kineja guru dapat digunakan oleh guru, kepala sekolah dan pengawas. untuk merefleksi diri. Penilaian dilakukan secara baik dan objektif akhirnya pendidikan yang berkualitas dan berdaya saing dapat segera diwujudkan dalam membangun bangsa yang bermartabat. 
190 Kebijakan Supervisi Dan Penilaian Kinerja Guru Guna Mewujudkan Kompetensi, Kinerja, Mutu Pendidikan Di Sekolah Dasar Menuju Abad 21 - Fitriadi, Sufyarma Marsidin, Ahmad Sabandi DOI: https://doi.org/10.31004/edukatif.v2i2.120

Penilaian kinerja dilaksanakan oleh pengawas sekolah bertujuan untuk :

1. mendapatkan data tentang pelaksanan tugas inti, fungsi dan tanggung jawab kepala sekolah dalam melaksanakan fungsi manajerial dan suvervisi pada sekolah yang dipimpinnya.

2. mendapatkan data hasil pelaksanan tugas dan tangung jawabnya sebagai pemimpin sekolah.

3. menentukan kualitas kerja atas kepala sekolah sebagai dasar dalam promosi dan penghargaan yang diberikan padanya.

4. menentukan program peningkatan kemampuan profesional kepala sekolah dalam konteks peningkatan tingkat pendidikan pada sekolah yang dipimpinnya.

5. menentukan program umpan balik bagi peningkatan dan pengembangan diri dan karyanya.

\section{Aspek Penilaian Terhadap Penilaian Kinerja}

Berdasarkan Peraturan Menteri Pendidikan Nasional Nomor 16 Tahun 2007 tentang Standar Kualifikasi Akademik dan Kompetensi Guru dijelaskan bahwa standar potensi guru dikembangkan secara utuh ke dalam 4 kompetensi inti yaitu kompetensi pedagogi, kepribadi, sosialis dan propesional.

\section{Bentuk Instrumen Penilaian Dalam Penilaian}

\section{Kineja}

Jenis instrumen penilaian kineja guru dan kepala sekolah instrumen yang dilengkapi dengan rubrik penilaian untuk sumua indikator kinerja dari setiap tugas inti guru dan kepala sekolah.
Ruang lingkup dari penilaian kineja guru dan kepalas ekolah menggunakan skala penilaian (rating scale). Rating scale yaitu berupa daftar pernyataan dan pertanyaan yang harus dinilai oleh pengamat. Hasil penilaian terhadap pernyataan yang diajukan dinyatakan dalam 4 skala nilai yang diurutkan mulai dari nilai yang terendah (1) sampai nilai yang tertinggi (4) seperti uraian berikut ini :

Skor (1) Kineja hanya memenuhi 1 standar yang terdapat dalam deskriptor atau bukti fisik tentang pelaksanan tupok. Kineja pada tingkat ini menunjukan kategori termasuk rendah.

Skor (2) Kinerjanya tiga standar yang terdapat deskriptor bukti fisik tentang pelaksanan tupok. Level kinerja ini menunjukkan sedang.

Skor (3) Kinerja memenuhi standar yang terdapat deskriptor bukti fisik pelaksanan tugas inti. Kinerja pada tingkat menunjukkan kategori tinggi.

Skor (4) Kineja telah memenuhi semua standar terdapat dalam deskriptor fisik pelaksanan tugas inti. Kinerja level ini menunjukkan kategori sangat paling tinggi (PMPTK, 2008).

\section{Proses Penilain Kinerja Guru}

Penilain kinerja guru dan kepala sekolah dapat dilaksanakan dengan beberapa prosedur yaitu : 
191 Kebijakan Supervisi Dan Penilaian Kinerja Guru Guna Mewujudkan Kompetensi, Kinerja, Mutu Pendidikan Di Sekolah Dasar Menuju Abad 21 - Fitriadi, Sufyarma Marsidin, Ahmad Sabandi DOI: https://doi.org/10.31004/edukatif.v2i2.120

1. Tahapan Perencanaan

Pada tahapan sasaran akan dinilai yaitu kompetensi, keterampilan, dan tingkah laku diharapkan dari yang akan dinilai. Guru dan kepala sekolah merupakan dua jabatan yang berbeda, perbedaan dalam tangung jawab, sasaran dan standar kerjanya. Persiapan instrumen penilaian yang akan digunakan dalam PKG-PKKS.

\section{Tahapan Pelaksanaan}

Pada tahapan ini komitmen guru dan kepala sekolah dalam proses penilaian, penilai senantiasa memberikan masukan melalui komunikasi terbuka. yang mana data akan menjadi peran masukan untuk penilaian utama diakhiri tahun. Pelaksanan penilaian kinerja kepala sekolah dapat dilakukan sesuai dengan kebutuhan pengukuran kompetensi. Dua hal penting yang harus diperhatikan ketika melaksankan penilaian kineja kepala dari sekolah yaitu waktu dan frekuennsi pelaksanaan penilaian. Kelancaran penilaian kineja dilaksanakan berdasarkan persiapan yang matang baik waktu, instrumen indikator kompetensi yang sudah dirumuskan dalam agenda penilaian.

Berdasarkan Permendikbud No 65 Tahun 2013 bahwa penilaian proses pembelajaran harus menggunakan pendekatan penilaian yang autentik dengan menilai kesiapan siswa, proses dan hasil belajar secara keseluruhan. Keterpaduaan penilaian dari ketiga ranah tersebut akan dapat mengambarkan kapasitas, gaya dan perolehan hasil belajar peserta didik untuk menghasilkan dampak instruksional dan pengiring pada pembelajaran.

Oleh karena itu, dalam penyusunan perencanan membutuhkan pedoman yang akan membuat rencana proses pembelajaran berfungsi sebagaimana seharusnya. Perencanan proses pembelajaran seperti program penyusunan program tahunan, program semester, alokasi waktu, silabus dan RPP (Wina Sanjaya).

3. Tahapan Pemberian Nilai

Untuk tahapan ini penilai menetapkan nilai pada setiap indikator kineja setiap dimensi tugas utama guru. Sebelum pemberian nilai, penilai terlebih dahulu mengidentifikasi cara monitoring apakah indikator masing-masing kinerja guru teramati dan terpantau. Berikut ini penilaian dapat berupa :

a) rating numerika

b) frekuensi perilakuan (pilihan: selalunya, biasanya, kadang kala, dan seterusnya)

c) evaluasi (pilihan: sangat amat mampu, amat mampu, mampu dan seterusnya)

d) berdasarkan standar tertentu (pilihan: jauh melebihi standar, melebihi standar, sesuai standar, dan seterusnya)

4. Tahapan Persetujuan

Pada tahapan ini melaksanakan agar penilaian, penilai agar selalu menginformasikan kepada guru atau kepala sekolah hasil dari penilaian kinerja berdasarkan bukti catatan pada setiap indikator. Jikalau antara kedua belah pihak penilai dan yang dinilai sepakat maka keduanya menandatangani berkas laporan penilaian kineja. Keputusan terbuka untuk diverifikasi, jika guru dan kepala sekolah yang dinilai 
192 Kebijakan Supervisi Dan Penilaian Kinerja Guru Guna Mewujudkan Kompetensi, Kinerja, Mutu Pendidikan Di Sekolah Dasar Menuju Abad 21 - Fitriadi, Sufyarma Marsidin, Ahmad Sabandi

DOI: https://doi.org/10.31004/edukatif.v2i2.120

keberatan dengan hasil penilaian kinerja dapat mengajukan keberatan kepada kepala sekolah atau pengawas dan Dinas Pendidikan. Dinas Pendidikan menujuk asesor untuk bertindak sebagai moderator. Selanjutnya moderator melakukan penilaian kineja secara menyeluruh. Peguusul penilaian ulang agar harus dicatat dalam pelaporan akhir.

5. Tahapan Pelaporan

Pada tahapan laporan ini setelah rekap nilai kineja guru atau kepala sudah diperoleh penilai agar melaporkan hasilnya penilaian ke Dinas Pendidikan Kabupaten dan Kota dan Tim Penilai Angka Krediet (PAK) tahunan. Laporan hasil penilaian kineja dapat dimanfaatkan antara lain :

a) peran landasan penyusunan program kerja sekolah serta pembinaan guru dan kepala sekolah

b) untuk arsip kegiatan penilaian kineja yang telah dilaksnanakan

c) untuk bukti pertangungjawaban pengawas atas pelaksanan tugas inti dan fungsinya sebagai pengawas propesional.

Manfaat bagi Dinas Pendidikan hasil penilaian kinerja adalah :

1) untuk bahan dalam menilai kinerja guru dan kepala sekolah yang bersangkutan

2) sumber informasi agar tahu gambaran spesifik kinerja guru dan kepala sekolah

3) untuk dasar menentukan tindak lanjut pembinaan, fasilitasi terhadap peningkatan kinerja

4) untuk pertimbangan pemberian penghargaan, promosi, mutasi dan ensentif.

\section{SIMPULAN}

Penilaian kinerja sangat penting dilaksanakan. Proses penilaIan kineRja meliputi tahapan perencanaan, tahapan pelaksanaan, tahapan pemberiaa nilai, tahap persetujuan, dan tahap laporan. Melalui peningkatan kineja guru dengan menjadi guru yang profesional dengan beriring terlaksananya proses belajar mengajar dengan baik sesuai harapan Undang-undang Pendidikan Nasional dan akhirnya mutu pendidikan meningkat.

Penilaian kinerja yang baik dengan harapan dapat meningkatkan kualitas kerja individual seorang pendidik dan kepala sekolah. Setiap personil sekolah mempunyai kinerja unggul akan mengasilkan sebuah sekolah berkualitas, dan akhirnnya akan didapatkan bagi peserta didik. Sekolah terkenal qualitasnya memiliki daya tarik yang baik terhadap masyaakat maupun bakal peserta didik, sehinga sekolah dapat memilih bakal pelamar yang banyak.

\section{DAFTAR PUSTAKA}

Depdiknas .2003. Undang-undang No. 20 Tahun 2003 tentang Sistem Pendidikan Nasional. Jakarta: Depdiknas

E, M. (2012). Manajemen dan Kepemimpian Kepala Sekolah. Jakarta: Bumi Akasra.

Kemdikkbud.2013. Lampiran Peraturan Menteri Pendidikan \& Kebudayaan RI No.65 Tahun 2013 tentang Standar Proses Pendidikan Dasar \& Menengah. Jakarta: Kemendikbud

Mufah, J. (2011). Peningkatan Kompetensi Guru: Melalui Pelatihan dan Sumber Belajar Teori dan Praktik. Jakarta: Kencana.

Peraturan MenteriPendayagunaan Aparatur Negara dan ReformasiBirokrasi Nomor 16 Tahun 
193 Kebijakan Supervisi Dan Penilaian Kinerja Guru Guna Mewujudkan Kompetensi, Kinerja, Mutu Pendidikan Di Sekolah Dasar Menuju Abad 21 - Fitriadi, Sufyarma Marsidin, Ahmad Sabandi DOI: https://doi.org/10.31004/edukatif.v2i2.120

2009 tentang Jabatan Fugsional Gurudan AngkaKreditnya.

PeraturanMenteri Pendidikan Nasional Nomor 16

Tahun 2007 tentang Standar

KualifikasiAkademik dan Kompetensi

Guru.

PMPTK, D. (2008). Penilaian Kinerja Kepala Sekolah. Jakarta: Departemen Pendidikan Nasional.

PSDMPMP, B. (2012). Pedoman Pelaksanaan Penilaian Kinerja Guru. Jakarta: Kementerian Pendidikan dan Kebudayaan.

Sanjaya, Wina.2008. Perencanaan dan Desain Sistem Pembelajaran Jakarta: Kencana 